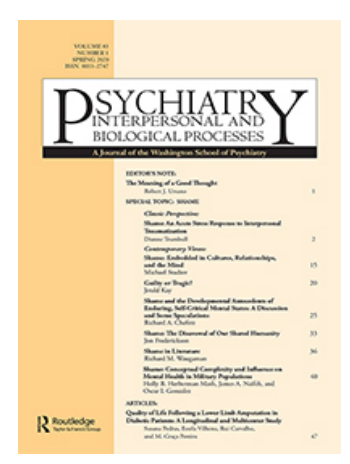

Psychiatry

Interpersonal and Biological Processes

ISSN: 0033-2747 (Print) 1943-281X (Online) Journal homepage: https://www.tandfonline.com/loi/upsy20

\title{
Quality of Life Following a Lower Limb Amputation in Diabetic Patients: A Longitudinal and Multicenter Study
}

\section{Susana Pedras, Estela Vilhena, Rui Carvalho \& M. Graça Pereira}

To cite this article: Susana Pedras, Estela Vilhena, Rui Carvalho \& M. Graça Pereira (2020)

Quality of Life Following a Lower Limb Amputation in Diabetic Patients: A Longitudinal and

Multicenter Study, Psychiatry, 83:1, 47-57, DOI: 10.1080/00332747.2019.1672438

To link to this article: https://doi.org/10.1080/00332747.2019.1672438

曲 Published online: 25 Oct 2019.

Submit your article to this journal 준

Џ Article views: 53

Q View related articles $\longleftarrow$

$\bigcup_{\text {CrossMark }}$ View Crossmark data $[\pi$ 


\title{
Quality of Life Following a Lower Limb Amputation in Diabetic Patients: A Longitudinal and Multicenter Study
}

\author{
Susana Pedras@, Estela Vilhena@, Rui Carvalho, and M. Graça Pereira®
}

Objective: Lower limb amputation (LLA) leads to several emotional and physical sequelaes that have a negative impact on individuals' life. The objectives of this study were: 1) to analyze the relationship between emotional reactions (anxiety, depression and traumatic stress symptoms) and functionality level, before and after a LLA due to diabetic foot ulcer, and mental/physical quality of life; and 2) to analyze the mediator role of social support between emotional reactions and mental/physical quality of life. Method: A multicenter, longitudinal study with four time assessments: before the surgery, one month, six months, and ten months after surgery, including 206 individuals hospitalized with diabetic foot ulcer indicated for a LLA. The instruments used were the following: Revised Impact of Event Scale; Barthel Index; Hospital Anxiety and Depression Scale and SF-36. Results: Anxiety symptoms before surgery and depression symptoms one month after surgery contribute to Mental Component Score (MCS) ten months after surgery. The level of functionality before and one month after surgery, traumatic stress symptoms one month after surgery as well as satisfaction with social support six months after surgery contribute to the Physical Component Score (PCS), ten months after surgery. Social support was a mediator between traumatic stress symptoms one month after surgery and PCS ten months after surgery. Conclusion: Identifying risk variables and the extent to which and when they affect mental/physical quality of life, will help to develop appropriate psychological interventions to promote quality of life in this population.

A lower limb amputation (LLA) leads to several emotional and physical sequelaes that have a negative impact on an individuals' life. Since some health indicators are the result of the individual's choices, the concept of health-related quality of life (HRQoL) has emerged emphasizing the power of individuals in changing their health (Ribu, 2010) and is

\footnotetext{
Susana Pedras is a Psychologist and a PhD student in the School of Psychology at the University of Minho, Braga, Portugal. Estela Vilhena is a Professor in the Technology School at 2Ai-Polytechnic Institute of Cávado and Ave, Barcelos, Portugal. Rui Carvalho is a doctor in the Division of Endocrinology, Diabetes and Metabolism at Centro Hospitalar Porto, Portugal. M. Graça Pereira is an Associate Professor with Aggregation in the School of Psychology at the University of Minho, Braga, Portugal.

Address correspondence to M. Graça Pereira, School of Psychology, University of Minho, Campus Gualtar, Braga 4710-057, Portugal. E-mail: gracep@psi.uminho.pt
} 
becoming a standard health outcome measure, especially for people with multiple disease or disability in daily clinical practice (Barofsky, 2012). Although LLA may be considered a life-saving treatment, individuals often experience negative psychological, physical and social effects at long-term, that have an impact on their overall quality of life (QoL) (Desmond \& Gallagher, 2010).

International studies have shown that amputees reported low levels of HRQoL when compared with the general population norms and controls (Amtmann, Morgan, Kim, \& Hafner, 2015; Kohler et al., 2017; Sinha \& Van Den Heuvel, 2011; Sinha, van Den Heuvel, \& Arokiasamy, 2011), particularly in physical, emotional and social dimensions, as well as pain, as opposed to mental health and vitality dimensions, satisfaction with life, and general health (Kohler et al., 2017). Longitudinal studies, in turn, have reached different conclusions, finding high or stable levels of HRQoL in amputee patients across time (Coffey, Gallagher, Desmond, Ryall, \& Wegener, 2014; Fortington, Dijkstra, Bosmans, Post, \& Geertzen, 2013). The main common link in these studies was the significant relationship between physical functioning, mobility, and QoL. The literature has suggested that the onset of a chronic illness or disability often leads to a change (not necessarily a reduction) in the overall QoL, given its impact on important patient's life domains (Bishop, 2005).Therefore, it is possible that after an amputation, there will be a change in the individual's assessment of QoL as a result of a change in the individual's internal perceptions. However, in order to provide a context, susceptible to change, it is necessary to know and control the factors that contribute and influence, positively or negatively, the HRQoL in this population.

Previous researchers have explored the role of functionality level, anxiety and depression symptoms and the association with HRQoL, in diabetic amputees. Functionality levels (impaired mobility) and their impact on activities of daily life (ADLs) are one of the factors that most contribute to a marked decreased in HRQoL, along with depression and anxiety symptoms (Anokye, Trueman, Green, Pavey, \& Taylor, 2012; Darnall et al., 2005; Fortington, Rommers, Geertzen, Postema, \& Dijkstra, 2012). There are some studies, although few, that indicated posttraumatic stress symptoms after a scheduled amputation (Desmond \& MacLachlan, 2006). In addition, the perception of social support, whether emotional, informational, or instrumental, has been indicated as a protective factor against the negative impact of LLA on HRQoL, especially during rehabilitation process and following hospital discharge (Gallagher, O’Donovan, Doyle, \& Desmond, 2011; Schoppen et al., 2003).

To our knowledge, this is the first Portuguese study to explore longitudinal relationships of emotional reactions and functionality, before and after surgery, and social support, six months after surgery, on HRQoL ten months after a LLA. We hypothesized that emotional reactions before surgery as well as functionality level will directly affect HRQoL and that social support will act as a mediator between emotional reactions after surgery and HRQoL ten months after surgery.

\section{METHOD}

\section{Study Design}

The present study is a longitudinal study that explored the characteristics of patients before and after amputation regarding psychological morbidity and HRQoL. A prospective design was chosen to establish an understanding of the hypothesized relationships. The study comprised four assessment moments and was conducted between June 2013 and January 2016, at six hospitals, at the Diabetic Foot Multidisciplinary Clinics and two Vascular Surgery Departments. The hypothesized model included emotional reactions (anxiety and depression symptoms) and level of functionality before and after surgery 
as well as traumatic stress symptoms after surgery as independent variables, social support as a mediator variable and HRQoL as a dependent variable. The model was adjusted for the confounding effects of age and sex.

\section{Participants}

A consecutive sample of 206 patients was included, out of 239 patients that were referred. Figure 1 shows the flowchart of data collection. Although 96 patients have collaborated in the last assessment moment, in order to analyze the HRQoL, ten months after LLA. Only data from 86 patients who completed the four assessment moments were used in this study. The study protocol was approved by the ethics committees of the hospitals where data collection occurred. All the participants were previously informed about the aims of the study, their participation was voluntary, and they signed a written informed consent. The inclusion criteria were: i) patients with Diabetes Mellitus, Type 2 (DMT2) and a Diabetic Foot Ulcer (DFU); ii) be indicated for a LLA surgery; and iii) be over 18 years old. The exclusion criteria included the diagnosis of a psychiatric disorder registered in the medical record.

\section{Procedures}

Patients were evaluated 24 hours (median: 1 day) before surgery (time 0: t0), one month after surgery (time1: $\mathrm{t} 1$ ), six months (time 2: $\mathrm{t} 2$ ), and ten months (time3: t3) after surgery, during their followup consultations at the hospital. Health professionals (nurses and physicians) identified patients who were scheduled for a LLA and the researcher invited them to participate in the study. Participants were hospitalized for an average of 10 days $(S D=10.99)$ before the first assessment ( $\mathrm{t} 0)$.

\section{Measures}

Demographic information was collected during the first assessment $(\mathrm{t} 0)$ and included the following: gender, age, education (years), marital (with or without a partner) and professional status (active or retired). Clinical data were recorded from the medical charts and included data about duration of DMT2 (years), history of previous ulcers (yes/no), presence of other complications of DMT2 (yes/ no), type of foot (neuroischemic or neuropathic), history of previous amputations (yes/ no), and the level of index amputation (minor or major).

Revised Impact of Events Scale (IES-R) (Weiss, 2007; Portuguese version by Pereira $\&$ Pedras, 2016). This scale assesses the presence of traumatic stress symptoms. It comprises 21 items with higher results indicating the presence of a high number of traumatic symptoms. In this study, the Cronbach's alpha was .94.

Hospital Anxiety and Depression Scale (HADS, Zigmond \& Snaith, 1983; Portuguese version by Pais-Ribeiro et al., 2007). This scale comprises 14 items, 7 items for anxiety and 7 for depression. Higher scores indicate higher levels of anxiety and depression. In this study, Cronbach's alpha for anxiety scale (HADS-A) was .86 and .88 for depression scale (HADS-D).

Barthel Index (BI, Wade \& Collin, 1988; Portuguese version by Araújo, Ribeiro, Oliveira, \& Pinto, 2007). This scale assesses the level of functionality for ADLs. The scale comprises 10 items with higher scores representing increased functionality. In this study, Cronbach's alpha was .87 .

Satisfaction with Social Support Scale (SSSS) (Ribeiro, 1999). This scale comprises 15 items with higher results indicating higher levels of satisfaction with social support. In this study, the Cronbach's alpha was .92.

Short Form Health Survey (SF-36) (Ware, Kosinski, \& Dewey, 1993; Portuguese version by Ferreira, Ferreira, \& Pereira, 2012). This scale assesses two summary measures of 


\section{9 patients were identified by the team to be included in the study}

33 patients were excluded from the initial sample:

7 refused participation; 5 had their surgeries cancelled; 2 died prior to surgery; 1 patient was in the intensive care unit; 2 participants were transferred to a different hospital; 2 participants showed major hearing loss and 14 received emergency amputations and were excluded due to procedural reasons

\begin{tabular}{|c|c|c|}
\hline $\begin{array}{c}\text { Baseline Assessment } \\
\text { (T0): } \\
206 \text { patients }\end{array}$ & $\Rightarrow$ & $\begin{array}{l}62 \text { patients did not participate at T1 } \\
\text { Excluded from the study at T0: } 35 \text { patients had their surgeries } \\
\text { cancelled; } \\
10 \text { patients withdrew or refused to continue follow-up; } \\
17 \text { patients were considered missing data: } 6 \text { died; } 2 \text { did not } \\
\text { attend the vascular or diabetic foot follow-up consultation; } 2 \\
\text { were transferred to a different hospital; } 3 \text { had cognitive } \\
\text { impairment; } 3 \text { patients were lost due to schedule mismatches; } \\
1 \text { did not have a vascular or diabetic foot post }\end{array}$ \\
\hline 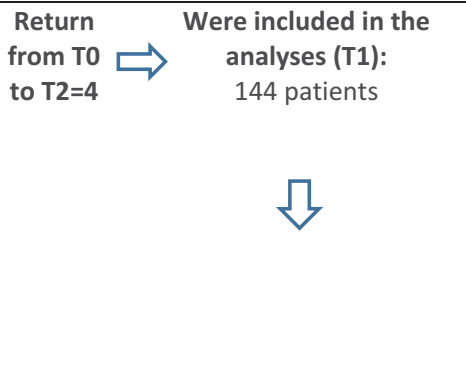 & $\vec{r}$ & $\begin{array}{l}52 \text { patients did not participate at T2 } \\
4 \text { patients withdrew or refused to continue follow-up; } \\
42 \text { patients were missing data: } 10 \text { patients died; } 6 \text { patients } \\
\text { had acute cognitive impairment after surgery; } 18 \text { did not have } \\
\text { a vascular or diabetic foot post-surgery consultation; } 1 \text { was } \\
\text { transferred to a different hospital; } 2 \text { did not attend the } \\
\text { vascular or diabetic foot follow-up consultation; } 3 \text { were } \\
\text { unreachable; } 1 \text { patient was lost due to schedule mismatches. } \\
6 \text { patients that participated at T0, and was expected that } \\
\text { participate at T2: } 1 \text { refused; } 2 \text { did not have a vascular or } \\
\text { diabetic foot consultation; }\end{array}$ \\
\hline $\begin{array}{c}\begin{array}{l}\text { Return } \\
\text { from } \mathrm{T} 1 \\
\text { to } \mathrm{T} 3=8\end{array} \Rightarrow \begin{array}{c}6 \text { Months after Surgery } \\
(\mathrm{T} 2): 107 \text { patients }\end{array} \\
\square\end{array}$ & $\Rightarrow$ & $\begin{array}{l}11 \text { patients did not participate at T3 } \\
2 \text { patients withdrew from the study } \\
15 \text { patients were missing data: } 4 \text { patients died; } 9 \text { did not have } \\
\text { a vascular or diabetic foot consultation; } 2 \text { did not attend the } \\
\text { vascular or diabetic foot follow-up consultation. }\end{array}$ \\
\hline $\begin{array}{l}10 \text { Months after Surgery } \\
\text { (T3): } 96 \text { patients }\end{array}$ & $\Rightarrow$ & $\begin{array}{l}22 \text { patients that participated at T1 and was expected that } \\
\text { participate at T3: } 11 \text { did not have a vascular or diabetic foot } \\
\text { consultation; } 2 \text { did not attend the vascular or diabetic foot } \\
\text { follow-up consultation; } 4 \text { patients still had cognitive } \\
\text { impairments after surgery; } 2 \text { still in a different hospital; } 3 \\
\text { patients still unreachable. }\end{array}$ \\
\hline \multicolumn{3}{|c|}{10 Months after surgery 86 patients participated in the four time points of assessment } \\
\hline
\end{tabular}

FIGURE 1. Flowchart of data collection.

quality of life: The Physical Component Score (PCS) and the Mental Component Score (MCS), and a high score indicate a good HRQoL in PCS and MCS. The Cronbach alpha in this study for both Summary Components Score was .89.

\section{Statistical Analysis}

Descriptive statistics were performed to describe sociodemographic and clinical characteristics of the sample. Univariate analyses were used to explore and compare 
the participants and the dropout group. Group comparisons for demographic, clinical and psychological characteristics were performed by independent-samples t-test for continuous data and Chi-squared test for categorical data. Results were considered statistically significant if $p<.05$. All analyses were conducted with SPSS 23.0 (Corp, I. B. M., 2013).

Regarding the relationship between sex and age, depression, anxiety and traumatic stress symptoms, functionality, and social support in HRQoL, a path analysis model was performed in order to explore the relationships of pre-and post-surgery variables along with MCS and PCS. The adequacy of the model was assessed according to the goodness of fit indexes. Comparative Fit Index (CFI> 0.90 suggests a good fit) and Root Mean Square Error Approximation (RMSEA) (values less than 0.05 indicate a good fit until 0.08 are considered acceptable) were used (Bentler, 1990). A nonsignificant $p$ value $(p>.05)$ and the ratio $\left(S-B_{x} 2\right) / d f<3$ represent a good model fit. Based on multivariate Lagrange Multiplier (LM) tests, post-hoc modifications to the proposed model were made to add new paths as necessary. The significance of all direct and indirect effects was evaluated to determine which variables had a direct and indirect impact on MCS and PCS. The $R^{2}$ values were calculated for all predictors, and outcome variables determine the proportion of explaining variance in outcome (Hu \& Bentler, 1999). Initially, the model included demographic variables (age and sex), to control for these covariables. Since none of these variables were statistically significant in the model, they were removed. Analyses were conducted with the EQS 6.1 package (Bentler, 1995).

\section{RESULTS}

\section{Participant Characteristics}

Of the 206 patients in the initial sample, a total of 86 patients who completed all instruments in the four assessments, were included in the analysis. The sample consisted of $73.3 \%$ male patients $(n=63)$, with a mean age of 63 years $(S D=10.8$, ranging from 36 to 90 years) and 5 years of formal education $(S D=3.40)$. The majority of the sample had a partner $(69.8 \%)$ and was retired $(67.4 \%)$. Regarding clinical characteristics, the mean duration of DMT2 was 208 months $(S D=141.86$, i.e. 17 years $)$ and patients reported a history of previous ulcers for 45 months ( $S D=57.79$, i.e., 4 years). The sample had other diabetes-related complications and $73.3 \%$, presented a neuroischemic foot. Half of the sample was already amputated, i.e. $23.3 \%$ had a major and $76.7 \%$ a minor amputation. Regarding the index amputation (the level of amputation scheduled at baseline assessment-t0), $18.6 \%$ patients were indicated for a major amputation and $81.4 \%$ for a minor amputation.

There were significant differences between those who collaborate in the study and the dropout group, on ulcer duration $(t(204)=.239, p>.05)$, and history of previous amputations $\left(\mathrm{X}^{2}=.348, p>.05\right)$ i.e. participants in the dropout group had a longer ulcer duration and history of previous amputations. In the other sociodemographic, clinical and psychological characteristics, there were no significant differences.

\section{Path Analysis to Explore the Relationships between Emotional Reactions, Functionality Level, before and after Surgery with MCS and PCS, Assessing the Mediator Role of Social Support}

Path analysis yields two types of results: estimates of the model's fit to the data, and estimates of the strength of relationships between variables in the model. Results showed a good model fit: $S-B_{\chi} 2=6.99$, $p=.32 ; \frac{S-B_{x_{6}^{2}}}{d f}=1.165 ; \quad$ CFI $=0.99$; RMSEA $=0.044(90 \% \mathrm{CI}=(0.00 ; 0.14)$. 
Anxiety $(\mathrm{b}=0.353)$ and depression symptoms $(b=0.239)$ at t0 were positively associated with anxiety symptoms at $\mathrm{t} 1$. Depression symptoms at $\mathrm{t} 0 \mathrm{had}$ a significant impact in depression symptoms at $\mathrm{t} 1$ $(b=0.464)$ and functionality at t0 $(b=0.517)$ in functionality level at $\mathrm{t} 1$. Anxiety at $\mathrm{t} 1$ $(\mathrm{b}=-0.447)$ and depression at $\mathrm{t} 0$ $(b=-0.275)$ had a negative and significant impact on social support at $\mathrm{t} 2$, while traumatic stress symptoms had a positive impact $(b=0.239)$. Regarding the outcome variables, results showed that, when all variables were included simultaneously in the model, social support at $\mathrm{t} 2(\mathrm{~b}=0.252)$ and functionality at t0 $(b=0.311)$ and at $\mathrm{t} 1(\mathrm{~b}=0.202)$ had simultaneous and positive impact on PCS, while traumatic stress symptoms had a significant but negative impact $(\mathrm{b}=-0.283)$ on PCS. In turn, anxiety symptoms at $\mathrm{t} 0(\mathrm{~b}=-0.237)$ and depression symptoms at $\mathrm{t} 1(\mathrm{~b}=-0.320)$ had both a negative impact on MCS. Results also showed a statistically significant indirect effect of social support, i.e. social support, at t2, partially mediated the relationship between traumatic stress symptoms at $\mathrm{t} 1$ and at PCS at t3 (Figure 2).

\section{DISCUSSION}

As far as the authors know, this is the first study exploring the relationship between emotional reactions and functionality level, before and after surgery, including social support during the rehabilitation process, as contributors to HRQoL ten months after surgery. Results revealed that elevated anxiety before surgery and depression symptoms one month after surgery were associated lower MCS ten months following the surgery. The level of functionality, before and one month after surgery, traumatic stress symptoms after surgery and the satisfaction with social support, six months after surgery, were associated to PCS, ten months after surgery. In addition, social support was a mediator between traumatic stress symptoms and PCS.

The negative relationship between emotional reactions (anxiety and depression symptoms) and functionality level before and after surgery show a need to implement psychotherapeutic approaches to deal and manage these symptoms in order to prevent the decrease of HRQoL (Darnall et al., 2005; Karanci \&

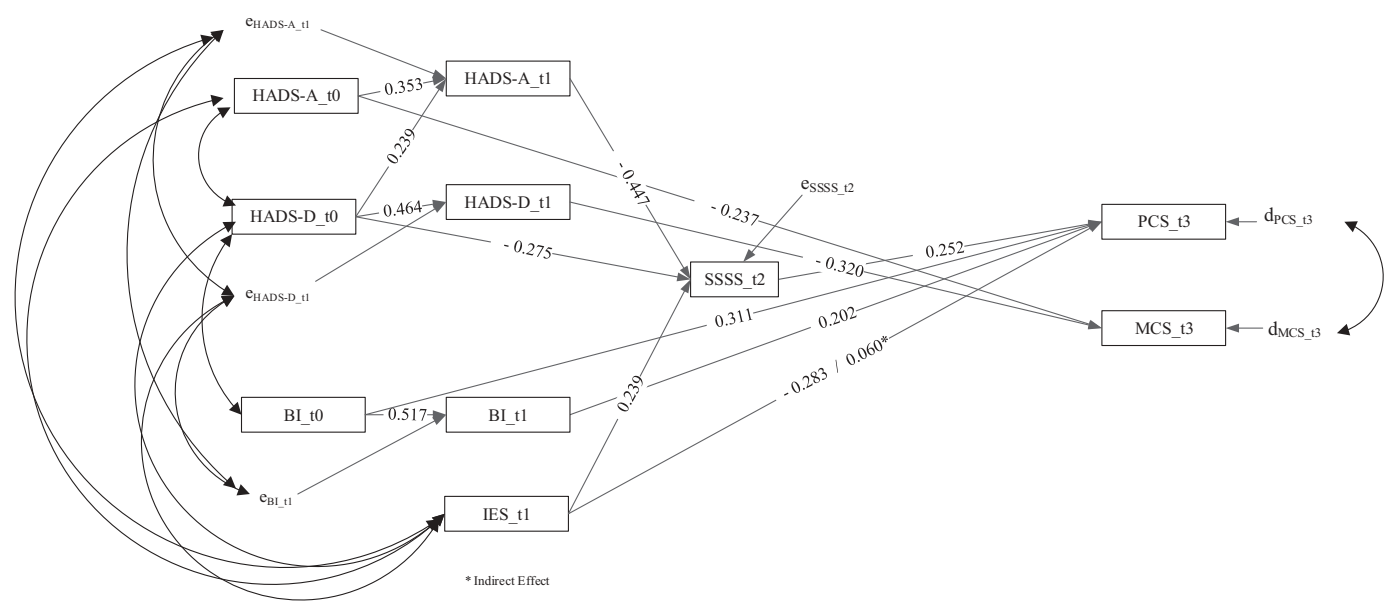

FIGURE 2. Standardized path coefficients.

Standardized path coefficients are presented. All paths are significant at $p<.05$. Fit indices: $S-B_{\chi} 2=6.99, p=.32$, $\mathrm{CFI}=0.99$, RMSEA = 0.04. HADS-A: Anxiety Scale; HADS-D: Depression Scale; BI: Barthel Index; IES: Impact of Event Scale Revised; SSSS: Satisfaction with Social Support Scale; PCS: Physical Component Score; MCS: Mental Component Score; $\mathrm{t} 0$ : pre-surgery, $\mathrm{t} 1$ : one month after surgery; $\mathrm{t} 2$ : six months after surgery; $\mathrm{t} 3$ : ten months after surgery. 
Dirik, 2003; Singh et al., 2009). Also, the functionality level at $\mathrm{t} 0$ and $\mathrm{t} 1$ contributed directly for PCS at t3. Rehabilitation goals are set taking into account the individual's capabilities, functional requirements and goals; and, ideally, the primary target is to restore the functionality level prior to LLA (Fiedler, Akins, Cooper, Munoz, \& Cooper, 2014). However, health professionals should be aware of the direct effect of pre and post functionality level on HRQoL ten months after surgery, indicating that rehabilitation should be more goal-oriented, not only to maximize function but also to improve HRQoL.

A result that deserves the most attention refers to the presence of anxiety symptoms before the surgery and depression symptoms after surgery as relevant predictors of MCS ten months after LLA. This result emphasizes the urgent need to address the patient's emotional reactions before and right after a LLA surgery since it impacts HRQoL, ten months after surgery. Anxiety symptoms before surgery may delay patients' recovery and delay wound healing, and compromising adherence to wound care. Also, anxiety symptoms can maintain emotional arousal that impairs the overall rehabilitation process (e.g. lack of motivation and a sense of hopelessness).In addition, the results suggest the need to screen and assess anxiety symptoms before surgery and the need to provide patients with a brief and focused intervention to address these symptoms (Fiedler et al., 2014; Tyrer et al., 2014). In addition, the results revealed that patients with depression symptoms one month after surgery are more likely to show a decrease in MCS, ten months after surgery. We hypothesize that these patients may not have the necessary internal resources to adjust to the amputation and, if unaided, the likelihood of achieving a good mental quality of life will be low.

Interestingly and unexpectedly, patients with traumatic stress symptoms had lower PCS in $\mathrm{t} 3$, but not MCS. This result should be emphasized not only because traumatic stress symptoms have been neglected by health professionals but also because there is empirical evidence suggesting that a single traumatic event may have negative health consequences (D’Andrea, Sharma, Zelechoski, \& Spinazzola, 2011), emphasizing the need for early assessment and intervention in this population.

Finally, the results of this study are consistent with most previous studies where a positive relationship between social support and HRQoL has been found (Gallagher et al., 2011; Schoppen et al., 2003). However, satisfaction with social support seems to have a protective effect only in PCS and not in MCS, as it mediated the symptoms of traumatic stress and PCS. This is an interesting finding and may be related to the high level of MCS in this sample, revealing however, an important goal for intervention in this population i.e. the promotion of social support during the rehabilitation process in order to improve PCS. Moreover, sex and age were non-significant in the model, which may be related to the low number of women in this sample, as well as to the great heterogeneity in the patients' age.

Some implications for clinical practice resulted from this research. Therefore, this study emphasizes the need to address patients' emotional reactions during the inpatient stay in order to adopt a more holistic care approach and promote HRQoL, in this population. Thus, an early referral to psychological support may prevent the decrease of HRQoL as well as mitigate the adverse effects of negative emotional reactions on the patients' rehabilitation process. Several studies have been supporting the efficacy of psychological interventions in hospitalized patients (Johnston \& Vögele, 1993). However, as far as the authors know, there is no psychosocial program designed specifically for patients with a LLA due to diabetes. The LLA population has the particularity of having a chronic disease that requires self- care management over time, along with the adjustment to the disability caused by LLA. Attention to the psychological needs of patients with LLA and their families should be part of a comprehensive rehabilitation program (to become more 
familiar with the psychological strategies used in this population, see Wegener, Hofkamp, \& Ehde, 2008). In addition, recently, Siersma et al. (2014) found that HRQoL predicts major amputation and death, in patients with DFU, which emphasizes the importance to assess HRQoL in this risk population. In addition, the promotion of social support in the community and the social network is essential to improve physical HRQoL. Providing practical assistance in day-to-day difficulties will help boost physical capacity and physical functioning, and more importantly, enhance patient self-efficacy. Finally, traumatic stress symptoms have a direct effect on PCS and not on MCS as expected, emphasizing the need of an appropriate psychological assessment and intervention for these symptoms.

To the best of our knowledge, this is the first study that specifically addresses the role of pre and post surgery variables contributing to HRQoL, ten months after surgery. Furthermore, unlike other studies that measured QoL through e-mail questionnaires or telephone interviews, in this study patients were assessed face-to-face by a trained health psychologist. The sample was collected at six hospitals, being therefore a multi-center study.

Despite the strengths of this study, it is important to acknowledge some limitations. Although, the sample was collected in six hospitals, one of the study's assets, all hospitals were located in the north of the country, where the amputation rate is the lowest in the country (de Diabetologia, 2014). Therefore, generalizations of the findings to patients from other regions of the country should be made with caution. Attrition might be a source of bias, but is an expected limitation of longitudinal studies. The great heterogeneity in the patients' age and sex may have influenced the results. However, the demographic characteristics of this population are well known and the data collection took place over three years suggesting that it would be difficult, if not impossible, to include more young and female patients.

\section{CONCLUSIONS}

By identifying risk variables and to what extent and when they directly or indirectly affect HRQoL before and after LLA, more appropriate psychological interventions can be implemented to promote HRQoL in this population. Functionality is a central factor, as expected. Emotional reactions before and after surgery are important to mental and physical HRQoL ten months after surgery, emphasizing the need for psychological assessment and intervention. Social support during rehabilitation period improved physical HRQoL ten months after surgery, emphasizing the need to promote social support after inpatient stay.

\section{ACKNOWLEDGMENTS}

The authors gratefully acknowledge the contributions of the Multidisciplinary Diabetic Foot Clinics of the following hospitals: CHP, CHSJ, CHVNG/E, CHTS, ULSAM and the Vascular Surgery Departments in Braga and CHSJ Hospitals. The authors also wish to thank all patients who agreed to participate in this study.

\section{DISCLOSURE STATEMENT}

No potential conflict of interest was reported by the authors.

\section{FUNDING}

This study was conducted at Psychology Research Center (PSI/01662), University of Minho, and supported by the Portuguese Foundation for Science and Technology and the Portuguese Ministry of Science, Technology and Higher Education through national 
funds and co-financed by FEDER through COMPETE2020 under the PT2020 Partnership Agreement (POCI-01-0145-FEDER -007653). This work was supported by a grant (SFRH/BD/87704/2012) from the Portuguese Foundation for Science and Technology

\section{ORCID}

Susana Pedras ๑ http://orcid.org/
0000-0001-5771-562X
Estela Vilhena @ http://orcid.org/
0000-0002-3063-5117
M. Graça Pereira $\odot$ http://orcid.org/
0000-0001-7987-2562

\section{REFERENCES}

Amtmann, D., Morgan, S. J., Kim, J., \& Hafner, B. J. (2015). Health-related profiles of people with lower limb loss. Archives of Physical Medicine and Rehabilitation, 96(8), 1474-1483. doi:10.1016/j.apmr.2015.03.024

Anokye, N. K., Trueman, P., Green, C., Pavey, T. G., \& Taylor, R. S. (2012). Physical activity and health related quality of life. BMC Public Health, 12(1), 624. doi:10.1186/1471-2458-12-624

Araújo, F., Ribeiro, J. L. P., Oliveira, A., \& Pinto, C. (2007). Validação do Índice de Barthel numa amostra de idosos não institucionalizados. Revista Portuguesa De Saúde Pública, 25, 59-66.

Barofsky, I. (2012). Why perform a quality or quality-of-life assessment? Quality of Life Research, 21(4), 633-636. doi:10.1007/s11136011-9962-z

Bentler, P. M. (1990). Comparative fit indexes in structural models. Psychological Bulletin, 107(2), 238. doi:10.1037/0033-2909.107.2.238

Bentler, P. M. (1995). EQS structural equations program manual (Vol. 6). Encino, CA: Multivariate software.

Bishop, M. (2005). Quality of life and psychosocial adaptation to chronic illness and disability: Preliminary analysis of a conceptual and theoretical synthesis. Rehabilitation Counseling Bulletin, 48(4), 219-231. doi:10.1177/ 0034355205048004

0301

Coffey, L., Gallagher, P., Desmond, D., Ryall, N., \& Wegener, S. T. (2014). Goal management tendencies predict trajectories of adjustment to lower limb amputation up to 15 months post rehabilitation discharge. Archives of Physical
Medicine and Rehabilitation, 95(10), 1895-1902. doi:10.1016/j.apmr.2014.05.012

Corp, I. B. M. (2013). IBM SPSS statistics for windows, version 22.0. Armonk, NY: IBM Corp.

D’Andrea, W., Sharma, R., Zelechoski, A. D., \& Spinazzola, J. (2011). Physical health problems after single trauma exposure: When stress takes root in the body. Journal of the American Psychiatric Nurses Association, 17(6), 378-392. doi:10.1177/1078390311425187

Darnall, B. D., Ephraim, P., Wegener, S. T., Dillingham, T., Pezzin, L., Rossbach, P., \& MacKenzie, E. J. (2005). Depressive symptoms and mental health service utilization among persons with limb loss: Results of a national survey. Archives of Physical Medicine and Rehabilitation, 86(4), 650-658. doi:10.1016/j.apmr.2004.10.028

de Diabetologia, S. P. (2014). Diabetes: Factos e números 2014: relatório anual do Observatório Nacional da Diabetes. Lisboa, Portugal: Sociedade Portuguesa de Diabetologia.

Desmond, D., \& Gallagher, P. (2010). Quality of life in people with lower-limb amputation. In Victor R. Preedy \& Ronald R. Watson (Eds.), Handbook of disease burdens and quality of life measures (pp. 3785-3796). USA: Springer.

Desmond, D. M., \& MacLachlan, M. (2006). Affective distress and amputation-related pain among older men with long-term, traumatic limb amputations. Journal of Pain and Symptom Management, 31(4), 362-368. doi:10.1016/j. jpainsymman.2005.08.014

Ferreira, P. L., Ferreira, L. N., \& Pereira, L. N. (2012). Medidas sumário física e mental de estado de saúde para a população portuguesa. 
Revista Portuguesa De Saúde Pública, 30(2), 163-171. doi:10.1016/j.rpsp.2012.12.007

Fiedler, G., Akins, J., Cooper, R., Munoz, S., \& Cooper, R. A. (2014). Rehabilitation of people with lower-limb amputations. Current Physical Medicine and Rehabilitation Reports, 2(4), 263-272. doi:10.1007/s40141-014-0068-8

Fortington, L. V., Dijkstra, P. U., Bosmans, J. C., Post, W. J., \& Geertzen, J. H. (2013). Change in health-related quality of life in the first 18 months after lower limb amputation: A prospective, longitudinal study. Journal of Rehabilitation Medicine, 45(6), 587-594. doi:10.2340/165019771146

Fortington, L. V., Rommers, G. M., Geertzen, J. H., Postema, K., \& Dijkstra, P. U. (2012). Mobility in elderly people with a lower limb amputation: A systematic review. Journal of the American Medical Directors Association, 13 (4), 319-325. doi:10.1016/j.jamda.2010.12.097

Gallagher, P., O’Donovan, M. A., Doyle, A., \& Desmond, D. (2011). Environmental barriers, activity limitations and participation restrictions experienced by people with major limb amputation. Prosthetics and Orthotics International, 35(3), 278-284. doi:10.1177/0309364611407108

Hu, L. T., \& Bentler, P. M. (1999). Cutoff criteria for fit indexes in covariance structure analysis: Conventional criteria versus new alternatives. Structural Equation Modeling: a Multidisciplinary Journal, 6(1), 1-55. doi:10.1080/10705519909540118

Johnston, M., \& Vögele, C. (1993). Benefits of psychological preparation for surgery: A meta-analysis. Annals of Behavioral Medicine, 15(4), 245-256.

Karanci, A. N., \& Dirik, G. (2003). Predictors of pre-and postoperative anxiety in emergency surgery patients. Journal of Psychosomatic Research, 55(4), 363-369. doi:10.1016/s00223999(02)00631-1

Kohler, R. E., Tomlinson, J., Chilunjika, T. E., Young, S., Hosseinipour, M., \& Lee, C. N. (2017). "Life is at a standstill" quality of life after lower extremity trauma in Malawi. Quality of Life Research, 26(4), 1027-1035. doi:10.1007/s11136-016-1431-2
Pais-Ribeiro, J., Silva, I., Ferreira, T., Martins, A., Meneses, R., \& Baltar, M. (2007). Validation study of a Portuguese version of the hospital anxiety and depression scale. Psychology, Health o Medicine, 12(2), 225-237. doi:10.1080/ 13548500500524088

Pereira, M. G., \& Pedras, S. (2016). Adapted version of the IES-R to amputation. Version of the Research Group on Family Health and Illness. Braga, Portugal: School of Psychology, University of Minho.

Ribeiro, J. L. P. (1999). Escala de satisfação com o suporte social (ESSS). Análise Psicológica, 17 (3), 547-558.

Ribu, L. (2010). Quality of life in patients with diabetic foot ulcers. In Victor R. Preedy \& Ronald R. Watson (Eds.), Handbook of disease burdens and quality of life measures (pp. 2115-2134). USA: Springer.

Schoppen, T., Boonstra, A., Groothoff, J. W., de Vries, J., Göeken, L. N., \& Eisma, W. H. (2003). Physical, mental, and social predictors of functional outcome in unilateral lower-limb amputees. Archives of Physical Medicine and Rehabilitation, 84(6), 803-811. doi:10.1016/s0003-9993(02) 04952-3

Siersma, V., Thorsen, H., Holstein, P. E., Kars, M., Apelqvist, J., Jude, E. B., ... Mauricio, D. (2014). Health-related quality of life predicts major amputation and death, but not healing, in people with diabetes presenting with foot ulcers: The Eurodiale study. Diabetes Care, 37(3), 694-700. doi:10.2337/dc13-1212

Singh, R., Ripley, D., Pentland, B., Todd, I., Hunter, J., Hutton, L., \& Philip, A. (2009). Depression and anxiety symptoms after lower limb amputation: The rise and fall. Clinical Rehabilitation, 23 (3), 281-286. doi:10.1177/0269215508094710

Sinha, R., \& Van Den Heuvel, W. J. (2011). A systematic literature review of quality of life in lower limb amputees. Disability and Rehabilitation, 33(11), 883-899. doi:10.3109/ 09638288.2010 .514646

Sinha, R., van Den Heuvel, W. J., \& Arokiasamy, P. (2011). Factors affecting quality of life in lower limb amputees. Prosthetics and Orthotics International, 35(1), 90-96. doi:10.1177/0309364610397087 
Tyrer, P., Cooper, S., Salkovskis, P., Tyrer, H., Crawford, M., Byford, S., ... Murphy, D. (2014). Clinical and cost-effectiveness of cognitive behaviour therapy for health anxiety in medical patients: A multicentre randomised controlled trial. The Lancet, 383(9913), 219-225. doi:10.1016/S01406736(14)60646-2

Wade, D. T., \& Collin, C. (1988). The barthel ADL index: A standard measure of physical disability? International Disability Studies, 10 (2), 64-67.

Ware, J. E., Kosinski, M., \& Dewey, J. E. (1993). SF-36 health survey. Manual \& interpretation guide. Boston, MA: Quality Metric.
Wegener, S. T., Hofkamp, S. E., \& Ehde, D. M. (2008). Interventions for psychological issues in amputation: A team approach. In Pamela Gallagher, Deirdre Desmond, \& Malcolm MacLachlan (Eds.), Psychoprosthetics (pp. 91-105). London, UK: Springer.

Weiss, D. S. (2007). The impact of event scale: Revised. In John P. Wilson \& Catherin So-Kum Tang (eds.), International and Cultural Psychology (pp. 219-238). Boston,USA: Springer.

Zigmond, A. S., \& Snaith, R. P. (1983). The hospital anxiety and depression scale. Acta Psychiatrica Scandinavica, 67(6), 361-370. doi:10.1111/j.1600-0447.1983.tb09716.x 